\title{
A ARTE DE ESCREVER CARTAS E SUA APLICAÇÃO NAS PRÁTICAS ESCOLARES
}

\author{
Maria Lúcia da Cunha Victorio de Oliveira Andrade•
}

Cartas produzem memórias, que se desdobram em críticas, que desencadeiam cartas, que engendram memórias... E o grande circuito dos discursos, onde se pode observar a inscrição das trajetórias de leitor $e$ autor, de remetente $e$ destinatário. (Marilia RothierCardosø2000)

\section{Introdução}

A partir de algumas cartas selecionadas da correspondência pessoal de Machado de Assis, organizada por Sérgio Paulo Rouanet (2008), buscamos identificar e analisar as estratégias de envolvimento ou distanciamento presentes em quinze cartas, visando a caracterizar as Tradições Discursivas (TD), no que diz respeito à constituição do gênero epistolar (carta pessoal), que constituem o sistema discursivo das práticas sociais do século XIX.

As TD são aqui tomadas como modelos historicamente convencionalizados, propostos pela Lingüística Textual e Romanística Alemãs e que permitem reconhecer os textos como pertencentes a uma dada época. O estudo de tais modelos gerais, que servem como guia para as construções individuais, parte da convergência entre o estudo pragmático e o diacrônico, bem como de uma proposta de análise do discurso sob um prisma histórico.

Para Oesterreicher (1997), o conceito de TD é mais proveitoso que o de gênero, pois este se baseia nas semelhanças compartilhadas por determinados textos. Desse modo, esse conceito não pode explicitar as diferentes variantes de gêneros textuais/discursivos que conferem ao gênero um estatuto dinâmico, sua capacidade de ser tradição e inovação. Segundo o referido autor, as TD são gêneros textuais/discursivos, mas não se limitam a eles. Todas as regularidades que podemos identificar em um determinado gênero podem ser consideradas aspectos discursivotradicionais, isto é, são características de um gênero textual/ discursivo/ de uma tradição discursiva, mas não constituem isoladamente "tradições discursivas".

O gênero textual/discursivo é a fonte de todas as regularidades lingüísticas e pragmáticas de um texto e todos os aspectos como: estilo, tema, função, sintaxe, léxico,

\footnotetext{
- Professorala Áreade Filologiæ LínguaPortuguesa DLCV- Universidadele SãoPaulo.
} 
fórmulas etc., têm sua origem no gênero. Assim, o conceito de TD considera não somente a cristalização de um gênero, mas também o aspecto de sua variação e inovação.

A concepção de gênero mais aceita e que assume uma posição de destaque nos estudos linguísticos contemporâneos é a proposta por Bakhtin (2003), dado que o autor fornece subsidíos teóricos e categorias amplas que podem ser assimiladas por outras diversas correntes de pensamento relativo ao gênero de forma proveitosa (cf.Marcuschi 2008).

De fato, a teoria bakhtiniana apresenta um conceito de gênero bastante produtivo, desenvolvido a partir de macrocategorias que permitem explicar o funcionamento dos gêneros discursivos circulantes na sociedade. Bakhtin (2003: 262) define gênero discursivo como "tipos relativamente estáveis de enunciado", determinados pelas especificidades de uma dada esfera (ou campo) da atividade humana, cuja realização se manifesta na forma composicional, na temática e no estilo.

Nessa perspectiva, o campo delimita um modo específico de refratar a realidade, especialmente no que se refere às demandas de base sócio-econômica, orientando-a à sua própria maneira, visto que cada esfera tem uma função determinada na vida social. Dessa forma, o campo se constitui como "um espaço de refração que condiciona a relação enunciado/objeto de sentido, enunciado/enunciado, enunciado/co-enunciadores" (Grillo, 2005: 175). A religião, a escola, o jornalismo, a literatura, a publicidade são exemplos clássicos de campos (ou esferas).

A forma composicional, por sua vez, refere-se à estrutura textual, que funciona como elemento organizador do material discursivo em um determinado gênero. Trata-se da categoria por meio da qual o gênero é reconhecido, na medida em que consiste no elemento que pode ser mais facilmente depreendido na configuração textual. Esse componente, intrinsecamente ligado à esfera, é também extremamente sensível à escolha temática, que se constitui em um elemento determinante para a seleção de uma forma composicional.

Por temática de um gênero, Bakhtin entende os princípios de seleção dos assuntos, as formas definidas de ver e conceituar a realidade, o que inclui a profundidade e a orientação da abordagem (Bakhtin, 1993).

Já o estilo pode ser definido como a seleção dos recursos lexicais, fraseológicos e gramaticais de uma língua, aplicados a um texto, sob a coerção da forma composicional e da temática, elementos que determinam o grau de liberdade expressiva concernente a um determinado gênero.

Cabe destacar ainda, como corolário de uma concepção de linguagem fundamentada pelo princípio do dialogismo, que o texto é constitutivamente heterogêneo, polifônico e não se textualiza sob uma única forma, podendo nele aparecerem, concomitantemente, seqüências narrativas, explicativas, argumentativas; por exemplo, numa carta pessoal, cuja forma de base é a tentativa de estabelecer uma conversa à distância no espaço e no tempo podemos encontrar trechos narrativos, descritivos ou mesmo argumentativos. 
Trata-se, pois, de observar o dialogismo presente nas cartas selecionas. Essa marca de envolvimento está inscrita no texto por meio de marcas específicas, selecionadas pelo enunciador a partir de escolhas lexicais organizadas de tal modo que a sintaxe desse discurso pode revelar um uso significativo da língua numa dada época. Essa organização permite depreender a existência de um continuum no grau de proximidade/distância entre os enunciadores (remetente/destinatário).

\section{Tradições discursivas e historicidade dos textos}

Segundo Schlieben-Lange (1993), a história dos textos é independente da história das línguas e o estudo histórico das línguas deve levar em conta a história dos textos, pois esse estudo pode auxiliar a percepção da mudança lingüística.

As cartas pessoais do século XIX no Brasil conservam em sua construção composicional características de seu gênero de origem: as cartas do século XVI, XVII e XVIII. Estas, por sua vez, resultam dos modelos rígidos prescritos pela Ars Dictandi, que era composto pelas seguintes partes: saudação, introdução, narração, solicitação e conclusão.

Com o passar dos anos e a necessidades sociais esse esquema rígido foi sofrendo adaptações discursivas para que os textos pudessem atender aos usuários. $\mathrm{O}$ produto dessa mudança constitui o surgimento de tradições discursivas mistas, conforme Koch (1997) como o sermão, o aviso, a memória, o diário e as cartas de qualquer tipo.

A escritura de cartas sai do ambiente restrito dos palácios e ganha as ruas das cidades, como ocorre na França, onde se popularizou entre os indivíduos que viam nessa prática uma maneira de estabelecer contato com parentes e amigos distantes.É nesse contexto que surgem os secretários de cartas - compêndios com modelos de saudação e despedida, e inclusive regras de bons modos.

Ao tratar a respeito das práticas de escrita na Europa, entre os séculos XVI e XVII, Chartier (1999) menciona um fenômeno ocorrido na época com relação à obra La Secretaire a la Mode (O Secretario da Moda) de Jean Puget de La Serre, publicado em 1640, que se torna um best-seller de um gênero muito apreciado: as coletâneas de modelos de cartas. Esses secretários eram inicialmente destinados aos epistológrafos nobres ou burgueses, mas são incluídos no catálogo de editoras, que publicam livros de grande circulação, como a Bibliotèque Bleue. Entretanto, Chartier não acredita que esses modelos eruditos tenham realmente sido úteis aos leitores populares; de qualquer maneira a posse do livro já indica a popularização do gênero carta.

Cabe lembrar que a tradição discursiva de escrever cartas ultrapassou os limites das línguas francesa e italiana e que determinadas TD perdem sua "autoria", a partir do momento em que são incorporadas a comunidades lingüísticas que as adotam e atualizam. No que se refere à língua portuguesa, a tradição de escrever cartas começou a ser divulgada a partir de 1619, com a publicação da obra Corte na Aldeia 
de Francisco Rodrigues Lobo, considerado um dos primeiros teóricos da epistolografia em Portugal. A partir do século XVIII surgem vários compêndios ou secretários de cartas como a obra de Francisco José Freire intitulada O Secretario Portuguez, publicada em 1745, que teve várias edições revisadas e ampliadas ao longo dos séculos XVIII e XIX.

As cartas revelam a inovação verificada a partir da mistura e da convergência de tradições culturais, pois representam produtos que marcam o distanciamento comunicativo (ausência física do interlocutor), mas também realizam-se como elementos menos rígidos provindos da oralidade. Nessa perspectiva, pode-se afirmar que as cartas são uma interface entre a oralidade e a escritura, pois transitam entre um extremo e outro, dependendo do grau de intimidade entre os interlocutores

\section{A origem das cartas}

Desde a Antiguidade, a carta é talvez a TD mais conhecida dado que se refere a uma prática social destinada ao intercambio, cuja função dominante é comunicar algo a outro indivíduo que está distante. A escritura de cartas é a atividade mais divulgada para materializar o desejo ou a necessidade de interagir à distância, pois admite uma infinidade de temas e usos, diferentemente de outras TD. O termo carta, originalmente "designa o papiro preparado para escrever, e daí o rolo que por regra geral compreende um livro" (Curtius, 1955: 432).

A aparente forma fixa por meio da qual conhecemos a carta - fechada, selada, carimbada, introduzida pelo endereçamento inicial e concluída pelas saudações finais - surge a partir da pressão de várias forças. Nas palavras de Bouvet (2006: 12),

Uma carta não se restringe nem a uma situação prática (a ausência do destinatário), nem a uma conduta social (uma extensão da voz), nem a um referente objetivo (seu conteúdo), nem a determinações exteriores (as circunstâncias), nem a uma atitude psicológica (a sinceridade ou seu contrário, o artifício), nem a uma motivação interior (rogar, ferir, informar, convencer), nem a uns caracteres formais (uma retórica, um estilo), nem inclusive a uma enunciação dialógica que reúne não obstante o critério do reconhecimento mais constante. Com efeito, é possível imaginar um texto em primeira pessoa que não inscreva em nenhum lado seu destinatário e que seja igualmente destinado, posto em um envelope e dirigido a um destinatário. Podemos inclusive imaginar uma página em branco, sem o menor signo manuscrito, exceto a subscrição do destinatário. Uma carta é o conjunto desses elementos "postos em carta", ou seja, menos um estado do escrito que um movimento de escritura.

Ainda na visão de Bouvet, podemos dizer que a escritura de cartas é uma prática que existe a mais de quatro mil anos e perpassa diversas atividades sociais e 
em cada uma delas adquire configurações específicas. Entretanto, do ponto de vista composicional e temático, seu caráter proteiforme a faz redutível a um modelo único:

da carta breve às epistolas, da carta de negócios à de amor, da crônica à ficção, caracteriza-se por acolher uma temática variada expressa em múltiplos registros lingüísticos. Existe uma grande diversidade de tipos de cartas que se adequam às mais variadas circunstâncias de uso na vida social e adotam formatos diversos ao longo do tempo, o que as converteu em objeto de variadas classificações em todos os tempos (Bouvert, 2006:11-12).

Para muito pesquisadores da linguagem e dos gêneros discursivos (cf. Biber, 1988; Swales 1990; Silva, 1997), a carta evidencia sempre uma indagação: O que caracteriza o gênero carta que o diferencia de outros gêneros? Nas cartas há algo mais que uma simples escritura que se pode ver e alcançar. Isso faz com que a carta seja vista como uma escritura diferenciada e se reconheça sua especificidade. A carta obriga o enunciador a abrir, enquanto escreve, um espaço de diálogo com o interlocutor ausente. Ainda que haja particularidades entre os diversos tipos de cartas (carta pública, carta comercial, carta do editor, carta do leitor, carta-circular, carta aberta, carta-convite; carta-pedido; carta de aconselhamento; carta de agradecimento; carta de congratulações; carta pessoal; carta de amor, entre outras), em todas elas operam determinadas relações dinâmicas fundamentais que configuram a matriz epistolar; presença-ausência; oralidade-escritura; privado-público; envolvimentodistanciamento; fidelidade-traição; realidade-ficção. Sua singularidade e idiossincrasia recorrente na cultura pode explicar sua participação na língua e na literatura, conforme Andrés Jolles (1972) que inclui a carta nas formas simples.

A matriz epistolar pode ser observada na carta pessoal (caracterizada por apresentar escritura cotidiana e intima) ou missiva (enviada) como na carta compilada e publicada em Epistolários, Secretários, isto é, compêndios ou repertórios de cartas- modelo.

No decorrer dessa TD, verifica-se que a carta se atualiza de diversas maneiras, isto é, a matriz segue as variadas práticas sociais em que a escritura da carta se instaura e os distintos usos que dela são feitos. Em algumas se destacam determinados traços ou componentes (formato externo - cabeçalho, data, assinatura -, expressões formulaicas freqüentes em suas seções iniciais e finais), já em outras esses mesmos traços podem estar neutralizados ou podem adquirir matizes particulares (veja-se a carta do editor, por exemplo).

\section{A carta pessoal e sua caracterização}

O tipo de carta abordada neste trabalho e que se pode chamar de carta pessoal, favorece de alguma maneira a emergência do traço constituído pela franqueza nas manifestações que se escrevem com liberdade e que se apóiam na confiança que se 
deposita no destinatário (cf. Barrenechea, 1990). Pode-se ler as cartas selecionadas para análise como um intercambio entre enunciador e enunciatário e outra, mais específica, que comporta um diálogo entre duas pessoas que compartilham sentimentos, relações, ideias, isto é, uma história de vida em comum.

Como abertura de uma seqüência conversacional, a carta determina - pelo simples fato de ter sido enviada - uma obrigação de resposta por parte do destinatário, e se isto não ocorre, seria como o silêncio que se instaura numa interação face a face, permitindo inferências pragmáticas análogas.

Toda carta pode ser constituída por atos ilocutórios específicos (perguntas, promessas, pedidos, ordens, etc.) e gerar estratégias comunicativas de maneira semelhante ao que ocorre na conversação cotidiana. Com efeito, a carta é uma forma de diálogo, entretanto é sempre um diálogo que tem lugar na ausência de um dos participantes. Quando o enunciador escreve, seu enunciatário está distante, mas quando este último recebe a carta ela lhe falará sobre a distância. Nessa perspectiva, ambos o sujeitos jamais estão presentes ao mesmo tempo: a presença real de um somente pode ser acompanhada da reconstrução imaginária do outro, em um tempo e lugar distintos, nunca compartilhados.

Sem dúvida, a carta exibe e põe em prática a dialética entre a realidade concreta do ato de enunciação; instaura-se a presença de um sujeito real e sua transformação em figura do discurso (enunciador), em um efeito de discurso que se dá na e pela linguagem, e que apenas dentro dela se faz representável.

Para Violi (1987:89), "este sujeito é inapreensível, pois coloca-se sempre em outro lugar somente alcançável no simulacro da escritura". Para a referida autora, a dimensão comunicativa, que se apresenta como um dos traços mais específicos da escritura epistolar, caracteriza-se não somente pelo reenvio a uma situação interacional externa ao texto, mas principalmente pelas formas de sua inscrição textual, na modalidade específica de organização da estrutura discursiva.

O que caracteriza toda a carta é sua necessidade constitutiva de revelar as marcas da própria situação enunciativa (remetente/destinatário). A inscrição da estrutura comunicativa dentro do texto torna-se uma espécie de quadro enunciativo que, independentemente das diferenças de conteúdo, constituem a marca específica e inconfundível do gênero carta. De fato, a referência à situação de enunciação e de recepção, à organização espaço-temporal sofrerá variações de acordo com o tipo de carta; entretanto, mesmo as cartas mais impessoais apresentam as fórmulas consagradas de abertura e fechamento ("Prezado senhor"; "Ilustríssimo senhor";"Meu amigo"; "Atenciosamente"; "Teu sempre muito amigo"; "Adeus, meu bom amigo") garantindo a permanência do quadro enunciativo que caracteriza os textos epistolares.

A carta não deve ser vista apenas como uma forma textual que permite a troca de informação. Além de seu conteúdo, isto é, além do que efetivamente se diz, a carta - segundo Violi - sempre diz algo mais: fala por si mesma, revela o ato de ter sido escrita, é testemunha de sua própria existência. E nas palavras da autora: 
Sem dúvida, o fascínio mais sutil da carta está precisamente em sua dialética de proximidade e distância, de presença e ausência; a carta evoca a presença do outro e ao mesmo tempo o coloca em um lugar que é, pó definição, inalcançável: se escrevo é porque o outro não está aqui ou, se está, e precisamente para afastá-lo (Violi, 1987: 96)

\subsection{Categorias pragmático-discursivas do gênero carta}

A partir do quadro elaborado por Brandão, Andrade e Aquino (2009), em que as autoras apresentam as categorias pragmático-discursivas das cartas publicas e privadas, procuraremos analisar as cartas pessoais selecionadas para esta pesquisa. Segundo as respectivas autoras, as cartas apresentam as seguintes categorias:

Quadro 1

\section{CATEGORIAS PRAGMÁTICO-DISCURSIVAS DAS CARTAS}

\begin{tabular}{|c|c|c|c|}
\hline i Grau de exposição & $\begin{array}{l}\text { Pública } \\
\text { Privada }\end{array}$ & \multicolumn{2}{|c|}{$\begin{array}{l}\text { Administrativa, Jornalística } \\
\text { Administrativa, Familiar, entre amigos }\end{array}$} \\
\hline ii Grau de Centraçã & Tópica & $\begin{array}{l}\text { > centração } \\
\text { centração } \\
\text { < centração }\end{array}$ & \\
\hline iii Grau de planejam & ento e registro textual & $\begin{array}{l}\text { Planejado } \\
\begin{array}{l}\text { Relativamente } \\
\text { planejado }\end{array} \\
\begin{array}{l}\text { Relativamente não } \\
\text { planejado }\end{array}\end{array}$ & $\begin{array}{l}\text { Controlado (formal) } \\
\text { Semi-controlado } \\
\text { Livre (popular) }\end{array}$ \\
\hline $\begin{array}{l}\text { iv Grau de re } \\
\text { cumplicidade }\end{array}$ & ação de poder e & $\begin{array}{l}\text { Descendente } \\
\text { Horizontal } \\
\text { Ascendente }\end{array}$ & $\begin{array}{l}\text { Distância } \\
\text { Proximidade }\end{array}$ \\
\hline v Dimensões da açã & o discursiva & Seqüências & $\begin{array}{l}\text { Abertura } \\
\text { Narrativa } \\
\text { Descritiva } \\
\text { Explicativa } \\
\text { Argumentativa } \\
\text { Injuntiva } \\
\text { Dialogal } \\
\text { Fechamento }\end{array}$ \\
\hline
\end{tabular}


As condições de Distância e Proximidade que integram o item iv do Quadro 1, comportam, segundo as autoras, elementos determinados, que podem ser localizados de acordo com o subgênero focalizado Assim, podemos encontrar cartas em que se destacam maior ou menor grau de cumplicidade, de emoção, de afetividade, de expressividade, por exemplo.

Em relação ao processamento discursivo, os elementos indicados no Quadro 1 correlacionam-se, de tal sorte que podemos localizar um elemento do item $\underline{\mathrm{i}}$ que se correlaciona com outro elemento do item ii e este, por sua vez, com um elemento do item iii e assim por diante.

A configuração contextual do gênero carta comporta determinados elementos fixos e pelo menos um alternativo. Entre os elementos fixos, encontram-se os contextualizadores, que correspondem às indicações de local de procedência da carta, data e assinatura de autoria - trata-se de elementos que ancoram o texto. Quanto ao elemento alternativo, corresponde ao PS: Post scriptum. A ordem de apresentação desses elementos, de modo geral é a seguinte: local e data; endereçamento; abertura; desenvolvimento (seqüências); fechamento; assinatura; post scriptum.

\section{Correspondência particular de Machado de Assis}

Com base nas cartas publicadas pela Academia Brasileira de Letras, em 2008, sob a coordenação e orientação por Sérgio Paulo Roaunet na obra Correspondência de Machado de Assis- Tomo I (1860-1869), com comentários de Irene Moutinho e Silvia Eleutério, selecionamos dez cartas com o intuito de observar as marcas de oralidade presentes nesses textos, bem como as escolhas feitas pelo enunciador que possam revelar um grau maior ou menor de envolvimento ou distanciamento entre os interlocutores.

Segundo Rouanet, a década de 60 é muito importante na vida de Machado de Assis, dado que corresponde aos anos de formação e ao início da maturidade do escritor. Ainda segundo Rouanet (p. XVI):

Do ponto de vista biográfico, esses anos estão entre os menos conhecidos da vida de Machado. Suas cartas de mocidade contribuem para a reconstrução do que era o escritor durante esse período. Embora as cartas recebidas sejam mais numerosas que as expedidas, ajudam a desfazer a imagem de Machado como um homem ensimesmado, casmurro, frio nas relações humanas. Elas revelam, ao contrário, um jovem boêmio, namorador, com quem os amigos se abriam e aquém faziam confidências amorosas, no tom ultra-romântico de uma juventude que completara seu aprendizado literário lendo Musset e Álvares de Azevedo. 
As cartas que receberam nossa atenção apresentam mais de um tipo de simetria, isto é, apresentam relações de poder e cumplicidade dos seguintes tipos:

a) - ascendente: na carta 3, enviada ao bispo do Rio de Janeiro - D. Manuel do Monte Rodrigues de Araújo, Conde de Irajá, em 18 de abril de 1862, que evidencia um tratamento mais cerimonioso:

(1) Excelentíssimo reverendíssimo senhor,

No meio das práticas religiosas, a que as altas funções de prelado chamam hoje vossa excelência consista que se possa ouvir o rogo, a queixa, a indignação, se não é duro termo, de um cristão que é dos primeiros a admirar as raras e elevadas virtudes, que exornam a pessoa de vossa excelência:

Outro exemplo é a carta 75 remetida a José de Alencar, em 1868, em resposta à carta enviada por José de Alencar em 18 de fevereiro do mesmo ano:

(2) A Sua Excelência o Senhor conselheiro José de Alencar.

Rio de Janeiro, 29 de fevereiro de 1868.

Excelentíssimo Senhor,

É boa e grande fortuna conhecer um poeta; melhor e maior fortuna é recebê-lo das mãos de Vossa Excelência, com uma carta que vale um diploma, com uma recomendação que é uma sagração. A musa do senhor Castro Alves não podia ter mais feliz intróito na vida literária. Abre os olhos em pleno Capitólio. Os seus primeiros cantos obtêm o aplauso de um mestre.

b) - horizontal: nas cartas enviadas a sua futura esposa Carolina Xavier de Novaes (carta 81 e 82) e nas diversas cartas enviadas a amigos, como por exemplo Quintino Bocaiúva (cartas 7, 8, 54, 59, 63 e 68). As marcas lingüísticas significativas que orientam essa análise correspondem ao tratamento em $2^{\text {a }}$ pessoa do singular. Vejam-se os exemplos:

(3) [Rio de Janeiro,] 2 de março de [de 1869] Minha querida Carolina,

Recebi ontem duas cartas tuas, depois de dois dias de espera. Calcula o prazer que tive, como as li, reli e beijei! A minha tristeza converteu-se em súbita alegria. Eu estava tão aflito por ter notícias tuas que saí do Diário à 1 hora para ir a casa, e com efeito encontrei as duas cartas, uma das quais devera ter vindo antes, mas que, sem dúvida, por causa do correio foi demorada. Também ontem deves ter recebido duas cartas minhas; uma delas, a que foi escrita no sábado, levei-a no domingo às 8 horas ao correio, sem lembrar-me (perdoa-me!) que ao domingo a barca sai às 6 horas da manhã. Às quatro horas levei a outra carta e ambas devem ter seguido ontem na barca das duas horas da tarde. Deste modo, não fui eu só quem sofreu com demora de cartas. Calculo a tua aflição pela minha, e estou que será a última.

(4) [Rio de Janeiro,] 2 de março [de 1869].

Minha Carola. 
Já a esta hora deves ter em mão a carta que te mandei hoje mesmo, em resposta às duas que ontem recebi. Nela foi explicada a razão de não teres carta no domingo; deves ter recebido duas na segunda-feira.

Queres saber o que fiz no domingo? Trabalhei e estive em casa. Saudades de minha Carolina, tive-as como podes imaginar, e mais ainda, estive aflito, como te contei, por não ter tido cartas tuas durante dois dias. Afirmo-te que foi um dos mais tristes que tenho passado.

Para imaginares a minha aflição, basta ver que cheguei a suspeitar oposição do Faustino, como te referi numa das minhas últimas cartas. Era mais do que uma injustiça, era uma tolice. Vê lá; justamente quando eu estava a criar estes castelos no ar, o bom Faustino conversava a meu respeito com a Adelaide e parecia aprovar as minhas intenções (perdão, as nossas intenções!) Não era de esperar outra coisa do Faustino; foi sempre amigo meu, amigo verdadeiro, dos poucos que, no meu coração, têm sobrevivido às circunstâncias e ao tempo. Deus lhe conserve os dias e lhe restitua a saúde para assistir à minha e à tua felicidade.

(5) Rio de Janeiro, 29 de outubro de 1866.

Meu Quintino.

Sei pelas folhas do Pará que fizeste até ali uma boa viagem, e estimo d'alma que o mesmo sucedesse até New York. Imagino, meu amigo, que há de ser uma coisa triste e difícil o separar-se a gente de criaturas que lhe são caras; faço idéia do que terás sofrido. Ao menos, porém, se há compensação para isto, deves consolar-te um pouco com a idéia de que tens uma viva saudade em todos quantos apreciam o teu caráter e o teu coração, e que esses, como a tua família, têm um desejo: o de que voltes ao teu país, depois de preenchido o teu dever e garantido o teu futuro.

As dimensões da ação discursiva apresentam-se na forma de relatos ou pequenas narrativas de fatos particulares, como se pode verificar no trecho da carta 82 , colocado a seguir:

(6) Contou-me hoje o Araújo que, encontrando-se num dos carros que fazem viagem para Botafogo e Laranjeiras, com o Miguel, este lhe dissera que andava procurando casa por ter alugado a outra. Não sei se essa casa que ele procura é só para ele, se para toda a família. Achei conveniente comunicar-te isto; não sei se já sabes alguma coisa a este respeito. No entanto, espero também a tua resposta ao que te mandei dizer na carta de ontem - relativamente à mudança.

Em relação à centração tópica, as cartas selecionadas, por circularem mais entre amigos, apresentam tópicos discursivos variados, algumas tratam de assuntos pessoais, já outras dizem respeito ao trabalho do escritor, como por exemplo a carta 7 a Quintino Bocaiúva em que Machado pede o conselho do amigo.

(7) Meu amigo,

Vou publicar as minhas duas comédias de estréia; e não quero fazê-lo sem o conselho de tua competência.

Já uma crítica benévola e carinhosa, em que tomaste parte consagrou a estas duas composições palavras de louvor e animação.

Sou imensamente reconhecido, por tal, aos meus colegas de imprensa. 
Mas o que recebeu na cena o batismo do aplauso pode, sem inconveniente, ser trasladado para o papel? A diferença entre os dois meios de publicação não modifica o juízo, não altera o valor da obra?

É para a solução destas dúvidas que recorro à tua autoridade literária.

Há também cartas curtas que contêm agradecimentos, como por exemplo a de número $68 \mathrm{em}$ que Machado de Assis revela o seu reconhecimento a Quintino Bocaiúva, segundo Moutinho e Eleutério, "no momento em que deixava a folha liberal, após ser nomeado auxiliar da diretoria de publcação do Diário Oficial do Império do Brasil"' (p.212, nota 2)

(8) Meu Quintino,

Recebe apertado abraço pelas boas palavras que disseste hoje de mim. A mão que me fez entrar para a casa há 7 anos é a mesma que tão lealmente me dá o adeus da despedida. São coisas que não se esquecem. Crê na amizade do Teu do coração, Machado de Assis

Em trabalho direcionado às cartas pessoais, Silva (2002:55) destaca que as práticas epistolares já apontavam há muito séculos

a existência não apenas de um gênero, mas, sim, o surgimento de um sistema (ou constelação) de gêneros epistolares, no seio das atividades sociais de uma dada cultura, produzidos e difundidos em esferas sociais distintas, para responder às demandas sociais particulares dessa cultura.

Trabalhos sobre abertura e fechamento de correspondências afirmam que os textos produzidos atualmente, no meio digital e encaminhados via correio eletrônico (e-mail), nem sempre remetem à tradição, já que em número reduzido algumas dessas práticas mantêm as saudações (inicial e final).

Há que se estabelecer distinção entre expressões formulaicas, já cristalizadas e o enunciado introdutório e/ou finalizador de uma correspondência escrita.Sabemos que as aberturas e fechamentos são constitutivos do gênero carta, em qualquer possibilidade tipológica dessa organização genérica. Sua localização, por si, já constitui tradição. Resta localizar freqüência de formulações específicas utilizadas em uma determinada época, além de outras marcas lingüísticas representativas do estilo de determinado enunciador.

As cartas destinadas à correspondência pessoal são marcadas pela relação emotiva entre familiares e amigos. Para a época, assim como se observa ainda hoje, é polido iniciar cartas interessando-se primeiramente pela saúde do interlocutor para, em seguida, tratar-se de apresentar a do interlocutor, como se registra em muitas delas. Vejamos a carta 80 escrita por Vieira de Castro para seu amigo Machado de Assis

(9) Morada Porto, 11 de dezembro de 1868. 
e clínico peritíssimo.

Proteja-o nesse país com o seu grande talento, e faça-lhe

as honras da imprensa, sim?

Eu mando um milhão e abraços e profundíssimas

saudades ao meu querido Machado de Assis.

[Obrigado $]^{1}$

Vieira de Castro

[trecho descritivo]

[pedido]

[despedida]

[assinatura]

\section{A carta pessoal e a prática escolar}

Apesar das especificidades de cada modalidade da língua - oral e escrita -, a carta pessoal (escritura) estabelece vínculos com a conversação cotidiana (oralidade), que lhe confere marcas de oralidade, evidenciadas nos elementos verbais que envolvem a situação discursiva por ela simulada.

Como na conversação natural, a carta pode ser redigida a partir de atos de fala que são mencionados pelo enunciador ou mesmo por personagens destacadas em trechos narrativos que compõem o gênero. Por fim, não escapa ao enunciador (remetente) a preocupação com o uso de uma variante lingüística adequada ao contexto e a relação estabelecida com seu interlocutor (destinatário), visando a envolver esse interlocutor e buscando efeitos de sentido de humor, ironia, emoção, entre outros.

Nesse sentido, alguns gêneros textuais/discursivos são considerados essenciais para atender à realidade social e linguística do aluno, aprendiz da escrita. Dentre esses gêneros, pode-se citar a carta, pois sua produção atende ao que hoje se pretende seguir na escola: trabalhar a escrita, observando de um lado a relação oral/escrita, num continuum de proximidade e distância entre os participantes, e de outro, a necessidade de que a prática da escrita esteja voltada para situar o aluno como cidadão consciente do uso social de sua língua materna.

Priorizando esse sentido social da prática da escrita na escola, objetivamos o que pode revelar a construção da função-autor em textos escritos, considerando as condições dadas e, principalmente, os sujeitos envolvidos, dentre eles a figura do professor, como orientador da atividade.

Nessa perspectiva, este artigo focaliza a carta pessoal, como instrumento didático-pedagógico para o exercício da competência textual de alunos do ensino médio durante as aulas de língua portuguesa. Sugerimos que a produção da carta pessoal seja realizada dentro de uma sequência de atividades que a antecedem. Assim, antes dessa atividade, o professor pode trabalhar a interação face a face (oralidade), evidenciando quais são as suas características básicas, qual a variante lingüística empregada, quais recursos lingüísticos se destacam. Em outro aula, o professor pode trabalhar a atividade

\footnotetext{
1 Os colchetes indicam que a palavra é de difícil legibilidade. Essa é a forma escolhida pelas organizadoras para orientar o leitor.
} 
de retextualização de um diálogo entre amigos, evidenciando as etapas de sua transposição para a modalidade escrita, observando que elementos precisam ser eliminados ou substituídos. Em outro momento, o professor pode ler uma carta pessoal, e destacar, juntamente com a turma, quais elementos se evidenciam nesse gênero, como é composto o seu modo de organização (narrativo, descritivo, expositivo, etc) que elementos lingüísticos se tornam significativos, qual o estilo selecionado pelo enunciador. Por fim, o professor pode sugerir que os alunos escrevam uma carta para um colega de classe ou uma pessoa da família. O tema da carta pode ser livre ou ser escolhido de comum acordo entre o professor e a turma. Depois da elaboração das cartas, o professor pode selecionar algumas e ler junto com a classe, analisar os textos ou solicitar que os alunos façam comentários baseados no que foi estudado sobre o gênero carta pessoal, qual a diferença em relação ao e-mail, por exemplo.

Para finalizar esta proposta, reafirmamos que a carta pessoal é um texto exemplar para iniciar o estudante nos estudos de língua materna e de gêneros textuais/discursivos, servindo como meio para que o professor possa trabalhar as duas modalidades da língua, suas semelhanças e diferenças, bem como suas condições de produção.

\section{Conclusão}

Como texto destinado ao outro, a carta pessoal faz o escritor tornar-se "presente" a seu destinatário. E segundo Foucault (1992: 149-150), "presente não pelas informações que lhe dá acerca da sua vida, das suas atividades, dos seus sucessos e fracassos, das suas venturas ou infortúnios; presente de uma espécie de presença imediata e quase física".

Toda atividade de produção textual, e a carta é uma atividade constante na sociedade no século XIX, processa-se a partir do conhecimento de modelos de realizações discursivas já produzidos pela sociedade. Como se viu no decorrer deste artigo, esses modelos podem ser denominados TD e as pesquisas linguísticas têm-se revelado essenciais para o conhecimento dos processos de constituição de um gênero determinado, por permitir precisar historicamente sua configuração, a partir de certas tradições, que o constituem ao longo do tempo.

Para Kabatek (2006: 512), a repetição do preenchimento da superestrutura de um gênero estabelece uma relação de união entre atualização e tradição. $\mathrm{O}$ uso efetivo das práticas discursivas e a transmissão de seus respectivos modelos ao longo do tempo permitem a manutenção das características básicas, sem que se descartem as possíveis necessidades de adequação aos contextos de cada época. Na atualidade, a maioria das pessoas passou a redigir e-mails ao invés de cartas, dada a facilidade de sua construção e envio, já que o suporte material (a internet) estabelece vínculos e oportunidades de contato mais rápidos do que o correio tradicional, mas a estrutura composicional é basicamente a mesma da carta pessoal.

Para finalizar, é importante dizer que os textos conservados pela escrita, além de trazerem os traços linguístico-textuais da TD a que se vinculam, auxiliam na reconstrução do momento histórico e permitem recuperar as formas de pensar de um período a partir de sua produção textual. 


\section{Referências bibliográficas}

BAKHTIN, Mikhail (2003). Os gêneros do discurso. In: Estética da criação verbal. Trad. Paulo Bezerra. São Paulo: Martins Fontes, (Original russo, 1979).

BAKHTIN, Mikhail (1993). Formas de tempo e de cronotopo no romance: ensaios de poética histórica. In: Questões de literatura e estética: a teoria do romance. Tradução de A. F. Bernadini et al. 3. ed. São Paulo: Ed. da UNESP, p.211-362. (original russo de 1937-1938)

BARRENECHEA, Ana Maria (1990). La epístola y su naturaleza general. Dispositio. University of Michigan. XV, 39, p. 51-65

BIBER, Douglas (1988). Variation across speech and writing. Cambridge: Cambridge University Press.

BOUVET, Nora Esperanza (2006). La escritura epistolar. Buenos Aires: EUDEBA.

BRANDÃO, Helena Nagamine; ANDRADE, Maria Lúcia C. V. O. e AQUINO, Zilda Gaspar Oliveira de (2009) Cartas da administração privada publica e cartas particulares: estudo da organização discursiva. In: CASTILHO, Ataliba T. de (org). História do Português Paulista. Vol. 1 Estudos. Campinas: IEL/UNICAMP, p.

CARDOSO, Marília Rothier (2000). Carta do leitor. Reflexões a partir de uma seção de arquivo. In: GALVÃO, Walnice Nogueira e GOTLIB, Nádia Battella (2001) (orgs.) Prezado Senhor, Prezada Senhora. Estudo sobre cartas.São Paulo: Companhia das Letras, p. 333-339.

CHARTIER, Roger (1999). A História Cultural: Entre Práticas e Representações. (Tradução de Maria Manuela Galhardo). Lisboa: Editora DIFEL.

CURTIUS, Ernst Robert (1955) Literatura Europea y Edad Media Latina. México: Fondo de Cultura Económica.

FOUCAULT, Michel (1999). O que é um autor? São Paulo: Passagens.

GRILLO, Sheila Vieira de Camargo (2005). A noção de campo nas obras de Bourdieu e do círculo de Bakhtin: suas implicações para a teorização dos gêneros do discurso. Revista da ANPOLL 19: 151-184.

JOLLES, André (1976). Formas simples. Tradução de Álvaro de Cabral. São Paulo: Cultrix

KABATEK, Johannes (2006). Tradições discursivas e mudança lingüística. In: LOBO, Tânia; RIBEIRO, Ilza; CARNEIRO, Zenaide e ALMEIDA, Norma (orgs.): Para a Historia do Português Brasileiro VI - Novos dados, novas análises, Salvador: EDUFBA, Tomo II, 505-527. 
KOCH, Peter (1997). Diskurstraditionen:zu ihrem sprachtheoretischen Status und ihrer Dynamik. In: FRANK, Barbara; HAYE, Thomas; TOPHINKE, Doris (eds.). Gattungen mittelalterlicher Schriftlichkeit. Tübingen: Narr 1997 (ScriptOralia, 99), 43-79. Trad.: COSTA, Alessandra Castilho Ferreira da.

MARCUSCHI, Luiz Antonio (2008)..Produção textual, análise de gêneros $e$ compreensão. São Paulo: Parábola Editorial.

OESTERREICHER, Wulf (1996). Lo hablado en lo escrito. Reflexiones metodológicas y aproximación a una tipología. In: T. Kotschi/ W. Oesterreicher/ K. Zimmermann (eds.). El Español hablado y la cultura oral en España y Hispanoamérica. Frankfurt am Main: Vervuert/ Madrid: Hiberoamericana, p. 317-340.

OESTERREICHER, Wulf (1997): Zur Fundierung von Diskurstraditionen. In: Frank, Barbara; Haye, Thomas \& Tophinke, Doris (Hrsg.): Gattungen mittelalterlicher Schriftlichkeit. Tübingen: Narr. Tradução de Alessandra Castilho Ferreira da Costa.

ROUANET, Sérgio Paulo (org.) (2008) Correspondência de Machado de Assis, Tomo I (1860-1869). Rio de Janeiro: ABL

SCHLIEBEN-LANGE, Brigitte (1993 [1983]). História do falar e história da lingüística. Tradução de Fernando Tarallo et al.. Campinas: EDUNICAMP.

SILVA, Jane Quintiliano Guimarães (2002). Um estudo sobre o gênero carta pessoal: das práticas comunicativas aos indicios de intertextualidade na escrita de texto. Tese de Doutoramento. UFMG.

SILVA, Vera Lúcia Paredes (1997) Variações tipológicas no gênero textual carta. In: KOCH, Ingedore G. V. e BARROS, Kazue S. Monteiro de (orgs) Tópicos em Lingüística de Texto e Análise da Conversação. Natal: EDUFRN, p. 118-124.

SWALES, John (1990). Genre analysis. Cambridge: Cambridge University Press.

VIOLI, Patrizia (1987) La intimidad de la ausencia: formas de la estructura epistolar. Revista de Occidente, 68, p. 87-99. 